IRA-International Journal of Technology \& Engineering ISSN 2455-4480

Proceedings of the

International Conference on Science \& Engineering for Sustainable Development (2017)

Pg. no. 373-384

Published by: Institute of Research Advances https://research-advances.org/index.php/IRAJTE

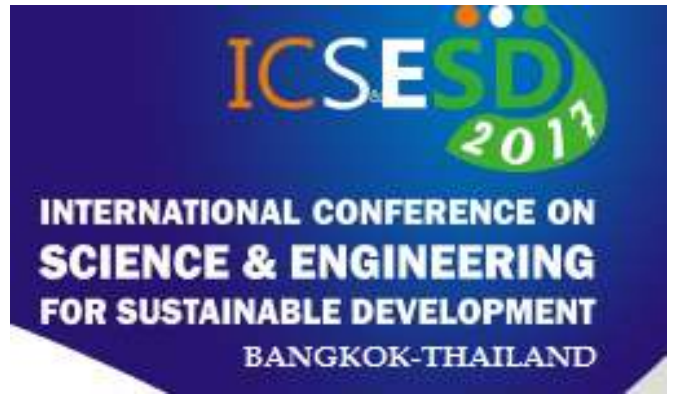

\title{
Review of Experimental Investigations in Friction Welding Technique
}

\author{
Gurunath Shinde ${ }^{1}$, Prakash Dabeer ${ }^{2}$ \\ ${ }^{1}$ Research Scholar, G.H.Raisoni College of Engineering and Management, Pune, India \\ ${ }^{2}$ Professor, Trinity College of Engineering and Research, Pune, India.
}

Type of Review: Peer Reviewed under the responsibility of the Scientific Committee of the Conference and The Institution of Engineers (India).

DOI: http://dx.doi.org/10.21013/jte.ICSESD201736

\section{How to cite this paper:}

Shinde, G., Dabeer, P. (2017). Review of Experimental Investigations in Friction Welding Technique. Proceedings of the International Conference on Science \& Engineering for Sustainable Development (2017), 373-384. doi:http://dx.doi.org/10.21013/jte.ICSESD201736

(C) International Conference on Science \& Engineering for Sustainable Development\& The Institution of Engineers (India).

\section{(cc) BY-NC}

This work is licensed under a Creative Commons Attribution-Non Commercial 4.0 International License subject to proper citation to the publication source of the work.

Disclaimer: The conference papers as published by the Institute of Research Advances (IRA) are the views and opinions of their respective authors and are not the views or opinions of the IRA. The IRA disclaims of any harm or loss caused due to the published content to any party. 


\section{ABSTRACT}

Friction welding is a solid state welding processes in which the weld is obtained by the heat generated due to forging and friction. Now a day's eco-friendly joining of dissimilar materials is the need of the industries. The advantages of friction welding process are reduction in production time and cost saving. Friction welding is classified into two types. One type is Inertia drive friction welding and the other is Continuous drive friction welding. In continuous drive friction welding one of the work pieces is held stationary while the other is held for a certain rotating speed. The two work pieces are brought together under certain friction pressure for a certain period of time known as friction time. Then, the rotation is stopped and upset pressure is applied for a certain upset time. Then, the spindle is disengaged and the component is unloaded. In Inertia drive friction welding one part is held stationary while the other is clamped in the chuck which is attached to the flywheel. The flywheel and chuck is rotated for a certain speed to store a predetermined energy. In this paper, review of friction welding on different materials and their weld ability has been discussed in brief.

Keywords: Solid State Process, Friction, Forging.

\section{INTRODUCTION}

The definition of friction welding in the American Welding Society (AWS) C6.1-89 standard is as follows: Friction welding is a solid-state joining process that produces coalescence of materials under compressive force contact of work pieces rotating or moving relative to one another to produce heat and plastically displace material from the faying surfaces. Under normal conditions, the faying surfaces do not melt. Filler metal, flux, and shielding gas are not required with this process ${ }^{6}$. In practice, friction welding is classified in two ways; continuous drive friction welding and inertia friction weld, In this study, continuous drive friction welding is used in which the rotational motion of the work piece is stopped after pressure has been loaded within a very short period of time. During the process, the frictional heat is generated in the interface up to maximum joint heat where plastic deformation is reached rapidly. Then the rotation is stopped to let the welded joint cool down freely. In friction welding, four parameters control the character of a weld: Rotational speed, relative velocity between the work pieces, frictional time and axial force. Figure 1 shows the basic layout of RFW equipment. Usually the structure is fairly rigid to provide stability to the equipment working at high speeds and is driven by high pressure forging. Modern equipment is automatic and allows all the parameters be adjusted, controlled and monitored directly on the control panel.

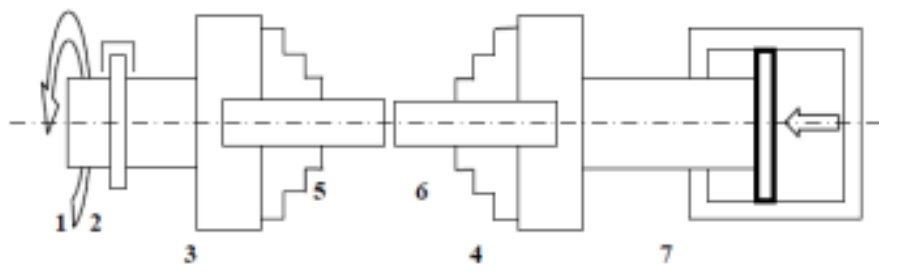

Fig. 1 Combined Attached Growth and Phyto Remediation Process 


\section{LITERATURE REVIEW}

Kimura et $a l^{[1]}$ described the effect of friction welding condition on joining phenomena, tensile strength, and bend ductility of friction welded joints between pure $\mathrm{Al}(\mathrm{CP}-\mathrm{Al})$ and austenitic stainless steel (AISI 304).The joint, which had high joint efficiency, the fracture on the CP-Al side with no crack at the weld interface, and no IMC interlayer on the weld interface, could be successfully achieved. Then, the joint should be made with a high forge pressure of $150 \mathrm{MPa}$, the opportune friction time at which the temperature on the weld interface reached about $573 \mathrm{~K}$ or higher, and those friction welding conditions were suggested for obtaining good joints with high joint efficiency and the bend ductility of $90^{\circ}$.

Liang et al $^{[2]}$ carried out study on 5A33 aluminum alloy bar with AZ31B magnesium alloy bar by continuous drive friction welding. The tensile strength of the joints increased with increasing friction time and on average the highest strength could reach up to $101 \mathrm{MPa}$ when friction time was 5s.All the friction welded samples failed at the friction interface during tensile test. The fracture appearances showed almost flat surface, so the fracture of the as-welded $\mathrm{Al} / \mathrm{Mg}$ joints in this experiment was brittle mode. A new reaction layer formed on the friction interface consisted of intermetallic compounds (IMCs) layer and $\mathrm{Mg}$ solid solution layer, and the IMCs were mainly Mg17Al12and Al3Mg2. The type of IMCs was variable with increasing friction time. Due to high micro-hardness of reaction layer, the micro-hardness value on the interface was dramatically larger than that of the $\mathrm{Mg}$ base material. The thickness of hardened layer in the $\mathrm{Mg}$ side and softened layer in the $\mathrm{Al}$ side increased with increasing friction time.

Pandia Rajan et $a l^{[3]}$ carried friction welding of two dissimilar materials of SA 213 tube to SA 387 tube plate using an external tungsten carbide tool to enhance and validate the mechanical and metallurgical properties. The two kinds of materials are taken in this investigation, where type 1 is tube without hole and type 2 is tube with hole on its circumference. It was observed that the optimal joint strength for the work piece without hole and with hole is $2980 \mathrm{MPa}$ and $2680 \mathrm{MPa}$, respectively. The value of Vickers hardness test was found in the welded zone to be much greater in work piece without hole that the work piece with hole is $292 \mathrm{Hv}$ and $217 \mathrm{Hv}$, respectively.

Pandia Rajan et al ${ }^{[4]}$ carried the friction welding of two dissimilar materials of SA 213 tube to SA 387 tube plate with three different filler materials as brass sheet, filler plate and steel ball using an external tungsten carbide tool to enhance and validate the flow of metal pattern toward the center of tool axis. The micro structural studies are made to reveal about the welding configuration locate and discover the flow of metal path toward the center of the workpiece, then it is followed by the hardness test which ensures a high hardness value at welded zone determines the flow of metal toward the center of the hole has strong bonding structure. Finally, the workpiece with filler material and steel ball is used by the radiography test and the analysis is done by using ANSYS software.

Pandia Rajan et al ${ }^{[5]}$ carried out to weld two dissimilar materials of SA 213 tube to SA 387 tube plate using an external tungsten carbide tool to enhance and validate the mechanical and metallurgical properties. The two kinds of materials are taken in this investigation, where type 1 is tube without hole and type 2 is tube with hole on its circumference. It was observed that the optimal joint strength for the work piece without hole and with hole are $3062 \mathrm{MPa}$ and $2845 \mathrm{MPa}$ respectively. The value of Vickers hardness test was found in the welded zone to be much greater in work piece without hole that the work piece with hole are $313 \mathrm{Hv}$ and $283 \mathrm{Hv}$ respectively.

Palanivel et $a l^{[6]}$ conducted study on Grade 2 titanium tubes with an outer diameter of $60 \mathrm{~mm}$ and wall thickness of $3.9 \mathrm{~mm}$.Lower range process parameter values produced weak joints due to pores and inadequate consolidation of the plasticized material. Process parameter values towards the higher end of the range also produced lower joint strengths due to the ejection of excessive hot material from the joint interface. The best joint strength was obtained at a rotational speed of $2200 \mathrm{rpm}$, friction time of $32 \mathrm{~s}$ and 
a burn off displacement of $1.4 \mathrm{~mm}$. All the tensile specimen failed either in the weld zone or in the base metal. The microstructure of the transition zone did not show the presence of an appreciable HAZ.

Safarzadeh et al ${ }^{[7]}$ presented study of mechanical properties and microstructure of friction welded Alumina-Mullite Composite with 6061 aluminum alloy. The welding process was carried out under different speeds (1250 and $1800 \mathrm{rpm}$ ) while force and time were kept constant. Studying the microstructure of the welding zone is important to investigate the relationship between microstructure and mechanical properties. It was found that in the friction welding of the ceramic composite to the aluminum alloy, the fracture proceeds mainly through the cleavage planes at a low speed while the fracture was occurred through the dimples at a high speed. The experimental results showed that a higher speed had a significant effect on the structure of the joint and also it had improved microhardness and bending strength.

Besler et $a l^{[8]}$ analyzed three materials (EN AW 5754H22, DC01 and Cu-DHP) by applying the method with flanged edges.The additional material required to form the weld is provided by the flanged edges of the parent sheet metal.The joint is formed by the relative motion between a rotating disc, which is applied with a crushing force, and two sheet metal parts. Bond strengths, as a percentage of the yield strength of the parent material, of around 95\% (DC01) 90\% (EN AW 5754H22) and 62\% (Cu-DHP) are achieved. Microstructural investigations reveal that a dynamic solid-state deformation and recrystallization of the additional flanged material results in a fine grain microstructure in the weld region. Reduced metallurgical changes along with minimized distortion and residual stresses in the parent material indicate low heat input. By creating a fine grain microstructure in the welding line, the friction crush welding method reveals great potential, especially for welding steel.

Li et al ${ }^{[09]}$ produced dissimilar joints between TC4 titanium alloy rod and SUS321 stainless steel rod by rotary friction welding (RFW). The influence of rotation speed was investigated on the morphologic distribution of intermetallics (IMCs) formed at the interface and on the mechanical properties that were assessed by tensile test and microhardness. Results showed that the morphology of IMCs, mainly Ti Fe2 and Ti Fe formed on SUS321 side, transforms from dispersive pattern to laminar pattern as the rotation speed increases from 400 to $1800 \mathrm{rpm}$ with a transition point around $600 \mathrm{rpm}$. The joint strength increases and then decreases after reaching a maximum value with increasing rotation speed. The highest tensile strength of $468 \mathrm{MPa}$, corresponding to the joint efficiency of $90 \%$, was achieved at $600 \mathrm{rpm}$, where the valley value of equilibrium interfacial temperature was obtained. All of the dissimilar RFWed joints failed completely in cleavage fracture mode along the boundary between IMCs layers and TC4 matrix.

Lakshminarayanan et al ${ }^{[10]}$ studied the properties of friction welded magnesium-titanium dissimilar joint using tensile testing coupled with digital image correlation, optical and scanning electron microscopy, Xray diffraction and microhardness measurements. Microstructurally different regions such as contact zone, dynamic recrystallized zone, thermo-mechanically affected zone, and partially deformed zone in the magnesium side were observed. No discernible regions were observed in the titanium side, as it had not undergone any significant plastic deformation. Phase analysis indicated that the aluminum from the magnesium side diffused toward the weld interface and formed a thin continuous intermetallic layer by reacting with the titanium. Microhardness mapping showed a steep hardness gradient from the titanium to magnesium side. Critical analysis is done on the tensile characteristics of the specimen and the response of the local regions to the deformation process is mapped.

Kumar et al ${ }^{[11]}$ reported sound weld zone of direct bonding between Ti-6Al-4V and SS304L through many trials, the joint was not successful. Here, the friction welding characteristics between Tie-Al-4V and SS304L into which pure oxygen free copper (OFC) was introduced as interlayer were investigated. Boxe Behnken design was used to minimize the number of experiments to be performed. The weld joint was analyzed for its mechanical strength. The highest tensile strength between Tie6Ale4V and SS304L 
between which pure copper was used as insert metal was acquired. Micro-structural analysis and elemental analysis were carried out by EDS, and the formation of intermetallic compound at the interface was identified by XRD analysis.

Kumar et al ${ }^{[12]}$ proposed method to decide near optimal settings of the process parameters in friction welding. The success of the friction welding process is based on various input parameters like friction pressure, friction time, upset pressure and upset time and output parameters like tensile strength, hardness and material loss. Ti-6Al-4V and SS304L (SS) materials were joined by friction welding process using interlayer techniques. The Box-Behnken design and response surface methodology (RSM) were applied to deciding the number of experiments to be performed and identify the optimum process parameters for obtaining better joint strength .Joint strength of $523 \mathrm{MPa}$ was obtained at a friction pressure of 12 $\mathrm{N} / \mathrm{mm} 2$, upset pressure of $40 \mathrm{~N} / \mathrm{mm} 2$, friction time of $1.2 \mathrm{~s}$ and upset time of $7 \mathrm{~s}$.

Mercan et $a l^{[13]}$ joined AISI 2205 duplex stainless steel, most commonly used in its class and economical AISI 1020 steel couple with low carbon content, using different operation parameters through friction welding. Tension test and rotary bending fatigue test were applied to the welded connections, and the impact of the welding parameters on fatigue strength was examined. It was discovered that when the welding parameters used in connecting AISI 2205 and AISI 1020 steel couple through friction welding were selected correctly, fatigue strength of the connection would increase compared to the main material, and incompliant parameters decreased fatigue strength.

Attallah et al ${ }^{[14]} \mathrm{FW}$ is known to result in a number of structural integrity issues due to the metallurgical and physical nature of Ti-alloys. First, due to the low thermal conductivity of titanium, its friction welds are typically associated with large residual stresses. Secondly, due to the severe thermo-mechanical deformation during friction welding, the welds are known to develop strong a-textures. Finally, the phase transformation that occurs during welding, and the subsequent transformation of martensite results in a micro structural in homogeneity phase to the across the weld regions that can be difficult to eliminate by post-weld heat treatment. In this work, an overview will be given on how these three concerns can be addressed through optimizing the process parameters to control the texture, residual stress development, as well as the microstructure-property in homogeneity across the welds regions. The work utilises a number of advanced characterization techniques, including synchrotron X-ray diffraction and electron microscopy.

Liang et al ${ }^{[15]}$ showed that intermetallic compounds (IMCs), consisting of phase $\beta$-A13Mg2 and $\gamma$ $\mathrm{Al} 12 \mathrm{Mg} 17$, were generated in the interfaces of the $\mathrm{Al}$ and $\mathrm{Mg}$ alloys. When the friction and forge pressure increased, the thickness of IMCs layer at the interfaces decreased as a result of more mass discarded from the welding interfaces. Heavy thickness of IMCs layer seriously deteriorated the mechanical properties of the joints. Microcracks were generated along the welded interfaces of all the welded samples. Formation of microcracks could be controlled effectively under the higher friction and forge pressure. Mechanical evaluations were conducted by determining microhardness and the tensile tests. It was observed that the tensile strength of the joints depended on the friction and forge pressure and the maximum tensile strength was $138 \mathrm{MPa}$.

Li et $a l^{[16]}$ carried out study on dissimilar joint of Ti6Al4V titanium alloy and SUS321 stainless steel by continuous drive friction welding. The effect of friction time on the mechanical properties was evaluated by hardness measurement and tensile test, while the interfacial microstructure and fracture morphologies were analyzed by scanning electron microscope, energy dispersive spectroscope and X-ray Diffraction. The results show that the tensile strength increases with friction time under the experimental conditions.Maximum average strength $560 \mathrm{MPa}$, which is $90.3 \%$ of the SUS321 base metal, is achieved at a friction time of $4 \mathrm{~s}$. For all samples, studied fracture occurred along the joint interface, where intermetallic compounds like FeTi, Fe2Ti, Ni3(Al, Ti) and Fe3Ti3O and many other phases were formed 
among elements from the two base metals. The width of intermetallic compounds zone increases with friction time up to $3 \mathrm{~lm}$, below which it is beneficial to make a strong metallurgical bond. However, the longer friction time leads to oversized flash on the Ti6Al4V side and overgrown intermetallic compounds. Finally the optimized friction time was discussed to be in the range of 2-4 s, under which the sound joint with good reproducibility can be expected.

Singh et al ${ }^{[17]}$ highlighted the role of globular microstructure on the weldability of semi-solid processed aluminum alloys via high temperature flow behavior. The investigation was carried out on the joining of thixocast A356 aluminum alloy components by friction welding. The magnitude of von Mises stress distribution during welding for the thixocast A356 sample is found to be lower than that of the conventionally cast sample, which is attributed to the difference in constitutive behavior at elevated temperature. Also, hardness profile and tensile studies indicate that the HAZ of friction welded samples of thixocast alloys is stronger than the corresponding base material. Overall, the study proves the viability of friction welding as a possible means of joining aluminum alloys cast in the form of a non-dendritic microstructure.

Gavade et al ${ }^{[18]}$ presented work deals with, effect of friction welding process parameters like friction pressure, friction time, and rotational speed on mechanical properties such as tensile strength, hardness and fatigue strength of aluminum 6061-T6 alloy. In this experiment the aluminum alloy 6061-T6 is a precipitation hardening alloy with high content of magnesium and silicon, presenting good mechanical properties and weldability and one of the most common aluminum alloys which is widely used for aerospace and automotive industrial applications. ANOVA of friction welding parameters indicates that friction pressure and rotational speed are significantly contributing towards friction welding performance Therefore; most influencing parameters are friction pressure and rotational speed for optimizing mechanical properties. The second influencing parameter is friction time. Friction pressure, friction time and rotational speed have a significant effect on tensile strength, hardness and fatigue strength. Mechanical properties like tensile strength, fatigue strength and hardness of friction welded joints found less than base metal strength.

Hazra et $a l^{[19]}$ joined nickel free high nitrogen austenitic stainless steel specimens continuous drive friction welding process by varying the amount of forge (upsetting) force and keeping other friction welding parameters such as friction force, burn-off, upset time and speed of rotation as constant at appropriate levels. The joint characterization studies include microstructural examination and evaluation of mechanical (micro-hardness, impact toughness and tensile) and pitting corrosion behavior. The integrity of the joint, as determined by the optical microscopy was very high and no crack and area of incomplete bonding were observed. Welds exhibited poor Charpy impact toughness than the parent material. Toughness for friction weld specimens decreased with increase in forge force. The tensile properties of all the welds were almost the same (irrespective of the value of the applied forge force) and inferior to those of the parent material. The joints failed in the weld region for all the weld specimens. Weldments exhibited lower pitting corrosion resistance than the parent material and the corrosion resistance of the weld specimens was found to decrease with increase in forge force.

Harraz et al ${ }^{[20]}$ reviewed aspects of rotary friction welding of high performance and high-temperature materials combined with lightweight alloys, and introduce a new realization for friction welding of incompatible bimetals. The hybrid joining between different bi-metallic materials has become extremely important in many industrial applications especially where the combination of strength and weight reduction is needed. High temperature materials such as high strength steels and Ti alloys combined with lightweight materials such as aluminum are widely being used in many industrial applications and particularly in the automotive and aerospace industries. Traditional fusion welding processes introduce significant amount of heat into the material and frequently lead to property deterioration, such as cracking and porosity during solidification. On the other hand the hybrid joining between different bi-metallic 
materials using conventional welding techniques are not possible. These problems could be overcome by the use of the recently developed solid state friction welding approaches.

Selvamani et al ${ }^{[21]}$ conducted study on $12 \mathrm{~mm}$ diameter AISI1035 grade steel rods with an aim to optimize the process parameters. The joints are made with various process parameter combinations subjected to tensile test. Rotational speed was found to have greater influence on tensile strength of the joints followed by Forging pressure and Friction pressure. The Vickers's micro hardness of the weld zone has increased at $59.7 \%$ of the base metal. This is a very less variation comparing with other fusion welding process. The heat affected zones shows the elongated ferrite, less quantity of ferrous carbide particles and less amount of pearlite. The fracture surface is evaluated by using scanning electron microscope.

Handa et al ${ }^{[22]}$ designed and fabricated experimental setup in order to accomplish friction welded joints between austenitic stainless steel and low-alloy steel. Thereafter, the effect of axial pressures on the mechanical properties of friction welded AISI 304 with AISI 1021 steels, produced by mechanical joining, have been investigated. Samples were welded under different axial pressures ranging from 75 to $135 \mathrm{MPa}$, at constant speed of $1250 \mathrm{rpm}$. The axial pressure has been found to be an influential parameter for the friction welding process.

With the increase in axial pressure, the tensile strength increases, the time taken before fracture also increases with the same and maximum time was achieved at $135 \mathrm{MPa}$, which was $34 \mathrm{~s}$. The maximum available tensile strength which was $466.83 \mathrm{MPa}$, was also available at this axial pressure. It has been observed that the impact toughness for the weldments follows the reverse trend; it declines as axial pressure increases. The maximum impact toughness values of 23 and $17 \mathrm{~J}$ both for Charpy and Izod impact were available at $75 \mathrm{MPa}$. With the increase in the axial pressure, the hardness at the center of weld cross-section increases. The maximum value of hardness, which was found to be $248 \mathrm{Hv}$, was available at $135 \mathrm{MPa}$ axial pressure.

Winiczenko et al ${ }^{[23]}$ presented the study of mechanical properties and microstructure of friction welded coupe of ductile iron with stainless steel. It was concluded that in case of bainitic ductile iron (BDI) the fracture precedes mainly through the cleavage planes. Moreover, the distribution of selected elements on both side of the joining interface was studied using EDS line and maps spectrometry. The EDS spectrometry showed some enrichment of ductile iron with $\mathrm{Cr}$ and $\mathrm{Ni}$ atoms close to the joint. The depth of $\mathrm{Cr}$ atoms penetration reached $50 \mathrm{um}$. The heat generated locally by friction increased the temperature in the area close to the interface even over the melting point of ductile iron. This was confirmed by metallographic which revealed the carbide eutectic enriched with $\mathrm{Cr}$ in ductile iron.

D Kumar et al ${ }^{[24]}$ investigated dissimilar metal mild steel-copper. The hardness at the mild steel side of the joint is higher than that at the copper side. The welded materials have lower hardness compared to their parent materials due to thermal effects of the friction welding. The welded rods show lower tensile strength compared to their parent rods. The average tensile strength and elongation of the dissimilar joints are $215 \mathrm{MPa}$ and 3\%, respectively, and the dissimilar joints fail in a ductile-brittle mixed fracture mode. Microstructure shows that the weld joint between mild steel-copper accompanied by the diffusion of copper into mild steel.

Seli et $a l^{[25]}$ evaluated of mechanical and interfacial properties of friction welded alumina-mild steel rods with the use of Al6061 sheet. The bonds were attained through interfacial interlocking and intermetalllic phase formation with average bending strengths in the range of 40 to $200 \mathrm{MPa}$ and insignificant hardness change in the parent alumina and mild steel. A preliminary simulation was made to predict the deformation, stress, and strain and temperature distribution during the joining operation using a fully coupled thermo-mechanical FE model. The hardness value for the mild steel part slightly increased 
toward the joint because of the formation of aluminium-mild steel intermetallic phase but this was not happen in the alumina part. Thinner interlayers could not maintain the increment of strength due to large material depletion. The strength was degraded by the existence of incomplete joint observed at the interface when a thinner interlayer was used.

Shubhavardhan et al ${ }^{[26]}$ studied solid state joining of dissimilar material AA6082 aluminum alloy and AISI 304 stainless steel, via continuous drive friction welding process, which combines the heat generated from friction between two surfaces and plastic deformation. The strength of the joints varied with increasing upset pressure and upset time keeping friction pressure and friction time constant. The joint strength increased, and then gradually decreased after reaching a maximum value, with increasing upset pressure and upset time. Joint strength depended on the size and shape of the tensile test piece. The process of friction welding between the aluminum alloy and the stainless steel is progressed from welding from the outer to the inner region; an unbounded region is retained at the centre of the weld interface with shorter upset time; longer upset time causes the formation of an intermetallic reaction layer at the weld interface; and the reaction layer grows as the upset time increases. Some of the welds had poor strength due to the accumulation of alloying elements at the joint interface. When the thickness of the reaction layer increased above a critical value, the joint was brittle and fractured at the weld interface. The joint was sound when there was no unbounded region and a thin reaction layer formed along the entire weld interface.

Ravikumar et al ${ }^{[27]}$ successfully welded 6061 Aluminum alloy with a maximum joint efficiency of around 70\%.All specimens failed in the weld region while some specimens exhibited welding defects.HAZ was found to be more for the defective weld pieces. Shrinkage of the specimen increased with increase in burn-off length and increase in upset pressure. The cumulative effect of both the above parameters affected shrinkage more. Weld times for all parameters varied from 13 to 15 seconds. Chemical composition of the aluminium used for welding, play an important role in deciding the properties of the weld. Major conclusions of microstructure evaluation of the friction welded joints revealed three distinct zones namely, base metal aluminium plastically deformed welded zone and parent metal aluminium. Hardness variations can be explained by dissolution and recrystallization phenomenon. Sandeep kumar et al ${ }^{[28]}$ carried out study on aluminum and mild steel.RPM has very little effect on UTS, Burn off length and friction time is more responsible for change in UTS values. As seen from previous papers burn off length has major effect on UTS, same is the case here where burn off length is more UTS is more.

Shubhavardhan et al ${ }^{[29]}$ showed joint strength during welding of AA6082 aluminum alloy and AISI 304 stainless steel increased and then decreased after reaching a maximum value, with increasing friction time. Sufficient heat to obtain a strong joint could not be generated with a shorter friction time. A longer friction time caused the excess formation of an intermetallic layer. However, some of the welds showed poor strength depending on some accumulation of alloying elements at the interface, which are the result of a temperature rise and the existence of intermetallic layers such as FeAl.EDX measurements clearly show that Steel-Al joints consist of some intermetallic compounds Hardness of both materials in the vicinity of the weld interface was higher than that of the base metals. In the micro-photos, the broken up aluminium oxide film resulted in increased deformation at the interface. Formation of an oxide in the joints causes a barrier that prevents diffusion.

Uday et $a l^{[30]}$ used a ceramic composite of YSZ-A12O3 for friction welding to $6061 \mathrm{Al}$ alloy. Alumina rods containing 0 and $25 \mathrm{wt} \%$ yttria stabilized zirconia were fabricated by slip casting process and subsequently sintered at $1600 \circ \mathrm{C}$. The diameter of both the ceramic and metal rods was $16 \mathrm{~mm}$. Rotational speeds for friction welding were between 630 and $2500 \mathrm{rpm}$. A friction pressure was maintained at $7 \mathrm{MPa}$ and friction time was kept constant. The mechanical strength of the friction welded A12O3-YSZ to 6061 alloy was determined with a four-point bend test and fracture failure surfaces. The experimental results 
indicated that the mechanical strength of friction-welded ceramic composite/6061 Al alloy components was observably affected by joining at the different rotational speeds selected. The fracture surface was observed to be different for ductile and brittle failure.

Fauzi et al $^{[31]}$ studied optical and electron microscopy as well as four-point bending strength and microhardness measurements to evaluate the quality of bonding of alumina and 6061 aluminum alloy joints produced by friction welding. The joints were also examined with EDX (energy dispersive X-ray) in order to determine the phases formed during welding. The bonded alumina-6061 aluminum samples were produced by varying the rotational speed but keeping constant the friction pressure and friction time. The experimental results showed that the effect of rotation speed and degree of deformation appears to be high on the $6061 \mathrm{Al}$ alloy than on the alumina part. It is discovered that the weld interface formed included three different regions: unaffected zone (UZ), deformed zone (DZ), as well as transformed and recrystallized fully deformed zone (FPDZ).Therefore, when rotational speed increases, the thickness of full plastic deformed zone (FPDZ) at the interface increases as a result of more mass discarded from the welding interface. It was also observed that rotational speed of $2500 \mathrm{rpm}$ can produce a very good joint and microhardness with good microstructure as compared to the other experimental rotational speeds.

Seli et $a l^{[32]}$ evaluated mechanical properties of mild steel and aluminum welded rods to understand the thermal effects, and an explicit one-dimensional finite difference method was used to approximate the heating and cooling temperature distribution of the joint. The thermal effects of the friction welding were observed to have lowered the hardness of welded materials compared to the parent materials. The tensile strength of the welded rods is lower than the parent rods due to incomplete welding. The preliminary predictions were compared to actual thermocouple data from welds conducted under identical conditions and were shown to be in fair agreement. The welded materials have lower hardness compared to their parent materials due to thermal effects of the friction welding. As a result of incomplete welding, the welded rods show lower tensile strength compared to their parent rods. A one-dimensional FD numerical model for continuous drive friction welding was developed according to the characteristics of the friction welding process. The predicted cooling temperature profile of the friction welding is in fair agreement with the experimental temperature.

Alves et al $^{[33]}$ studied solid state joints of dissimilar material AA1050 aluminum and AISI 304 stainless steel, which can be used in pipes of tanks of liquid propellants and other components of the Satellite Launch Vehicle. The joints were obtained by rotary friction welding process (RFW), which combines the heat generated from friction between two surfaces and plastic deformation. The results were analyzed by means of tensile tests, Vickers microhardness, metallographic tests and SEM-EDX. The strength of the joints varied with increasing friction time and the use of different pressure values. Joints were obtained with superior mechanical properties of the AA1050 aluminum, with fracture occurring in the aluminum away from the bonding interface. The analysis by EDX at the interface of the junction showed that inter diffusion occurs between the main chemical components of the materials involved. The RFW proves to be a great method for obtaining joints between dissimilar materials, which is not possible by fusion welding processes.

Rafi et $\mathrm{al}^{[34]}$ investigated friction welding of AA7075-T6 rods of $13 \mathrm{~mm}$ diameter with an aim to understand the effects of process parameters on weld microstructure and tensile properties. The results show that sound joints in AA7075-T6 can be achieved using friction welding, with a joint efficiency of $89 \%$ in as-welded condition with careful selection of process parameters. Friction pressure, spindle speed and burn-off length are the three most significant parameters affecting the joint strength in friction welding of AA7075. Use of higher friction pressure (114 MPa), higher spindle speed (2000 rpm), higher burn-off length $(4 \mathrm{~mm})$, and lower upset pressure (152 MPa) are recommended for friction welding of 13 mm diameter rods of AA7075-T6. Welds in all cases showed considerable differences in the amount of flash and in the TMAZ microstructures between stationary and rotating sides. 
Sketchley et al ${ }^{[35]}$ conducted study on Fe3Al based oxide dispersion strengthened (ODS) alloy used as tubes in advanced heat exchangers, and it is necessary to investigate methods of joining the alloy to itself, and to Haynes 230 alloy. Previous experience on iron aluminides has shown to be weldable by several processes, but it is known that fusion processes invariably lead to a loss of the $\mathrm{Y} 2 \mathrm{O} 3$ oxide dispersion which is an essential feature of ODS alloys. Therefore, solid state processes offer a potential advantage, and in this work continuous drive rotary friction welding has been investigated as a method to join the Fe3Al ODS alloy in both the recrystallized and unrecrystallized condition. Trials were also undertaken to join both recrystallised and unrecrystallized material to Haynes 230 alloy. All welds were made in 15-mm diameter material, using a conventional continuous drive rotary friction welding machine. Welds were evaluated initially using tensile tests, and detailed metallographic observations of the grain size, and the nature of the solid state interface between the materials. It was found possible to make high quality welds containing no flaws for a variety of welding conditions. The microstructural condition of the Fe3Al ODS alloy had no apparent influence on weldability, and no difficulty was encountered in making the dissimilar metal joints. The results obtained are discussed in terms of the microstructures obtained, and are compared with other studies on joining iron aluminates and ODS.

\section{CONCLUSIONS}

Friction Welding (FW) is a solid state welding process which produces welds due to the axial force to maintain contact of workpieces which are either rotating or moving relative to one another. Heat is produced due to the friction which displaces material plastically from the faying surfaces. In friction Welding no filler material, flux or shielding gas is required. No hazardous smoke, fumes or gases are generated. Oxide film formed which can be removed after weld. Strength of the weld obtained is more than base metal. Mass production is possible because of rapid action. This process is restricted to only round bar or tubes. Alignment of work pieces is important to enhance proper friction and forging action. Initial Investment is high.

In this paper, review of effect of various welding parameters on similar and dissimilar materials is discussed. Successful weld joints are obtained at optimal parameter values. Improper weld parameters led to defects and failure of the joints. Some numerical approaches are also used to predict the process mathematically. Friction welding can be successfully applied to aluminum, mild steel, stainless steel, Cast Iron and some non metallic materials etc. Applications of friction welding are automotive, aerospace, defense, marine, refineries etc.

\section{REFERENCES}

[1]M. Kimuraa, K. Suzukib, M. Kusaka, K. Kaizu, "Effect of friction welding condition on joining phenomena, tensile strength, and bend ductility of friction welded joint between pure aluminum and AISI 304 stainless steel" Journal of Manufacturing Processes 25 (2017) 116-125.

[2]Zhida Liang, Guoliang Qin, Peihao Geng, Fan Yang, Xiangmeng Meng (2017) "Continuous drive friction welding of 5A33 Al alloy to AZ31B Mg alloy" Journal of Manufacturing Processes 25 153-162.

[3]S. Pandia Rajan,S. Senthil Kumaran, L.A. Kumaraswamidhas , (2016) "An investigation on SA 213 tube to SA 387 tube plate with backing block arrangement in friction welding process" Alexandria Engineering Journal,55, $1255-1269$.

[4] Pandia Rajan, (2016) "An investigation of metal flow during friction welding of SA 213 tube to SA 387 tube plate with backing block" Alexandria Engineering Journal 55, 1187-1199.

[5]S.Pandiarajan,S.Senthil umaran, L.A. Kumaraswamidhas, R. Saravanan, "Interfacial microstructure and optimization of friction welding by Taguchi and ANOVA method on SA 213 tube to SA 387 tube plate without backing block using an external tool" Journal of Alloys and Compounds 654 (2016) 534-545.

[6]R. Palanivel, R.F. Laubscher, I. Dinaharan, An investigation into the effect of friction welding parameters on tensile strength of titanium tubes by utilizing an empirical relationship, Measurement (2016), doi: http://dx.doi.org/10.1016/j.measurement.2016.11.035.

[7] Marjan Safarzadeh, Ahmad Fauzi Mohd Noor and Uday M. Basheer, (2016) "Effect of friction speed on the properties of friction welded Alumina-Mullite Composite to 606. 
Aluminum alloy" Journal of the Australian Ceramic Society Volume 52[2], 2016, 134 - 142.

[8]Florian A. Beslera, Paul Schindele, Richard J. Granta, Michael J.R. Stegmüller,(2016) "Friction crush welding of aluminum, copper and steel sheet metals with flanged edges" Journal of Materials Processing Technology 234:72-83. [9]Xun Li, Jinglong Li, Zhongxiang Liao, Feng Jin, Fusheng Zhang, Jiangtao Xiong,(2016) "Microstructure evolution and mechanical properties of rotary friction welded TC4/SUS321 joints at various rotation speeds"doi:10.1016/j.matdes.2016.03.037.

[10]A.K. Lakshminarayanan, R. Saranarayanan, V. Karthik Srinivas, B. Venkatraman, (2015) "Characteristics of friction welded AZ31B magnesium-commercial pure titanium dissimilar joints" Journal of Magnesium and Alloys 3:315-321.

[11]R. Kumar, M. Balasubramanian, (2015) "Experimental investigation of Ti-6Al-4V titanium alloy and 304L stainless steel friction welded with copper interlayer", Defence Technology 1165-75.

[12]R.Kumar,M. Balasubramanian, (2015) "Application of response surface methodology to optimize process parameters in friction welding of Ti-6Al-4V and SS304 L rods" Trans. Nonferrous Met. Soc. China 25:3625-3633.

[13] Mercan, S., Aydin, S., Özdemir, N., (2015) "Effect of welding parameters on the fatigue properties of dissimilar AISI 2205 - AISI 1020 joined by friction welding”, International Journal of Fatigue,

[14] M M Attallah, M Preuss,S E Bray,(2015)“"Friction welding of titanium alloys: addressing the structural integrity issues through process optimisation"

[15] Zhida Liang, Guoliang Qin*, Liyuan Wang, Xiangmeng Meng, Fei Li,(2015) "Microstructural characterization and mechanical properties of dissimilar friction welding of 1060 aluminum to AZ31B magnesium alloy" Materials Science \& Engineering A.

[16]Peng Li, Jinglong Li, Muhammad Salman, Li Liang, Jiangtao Xiong, Fusheng Zhang, "Effect of friction time on mechanical and metallurgical properties of continuous drive friction welded Ti6Al4V/SUS321 joints" Materials and Design 56 (2014) 649-656

[17] Shailesh K. Singh, K. Chattopadhyay, G. Phanikumar ,P. Dutta, (2014) "Experimental and numerical studies on friction welding of thixocast A356 aluminum alloy” Acta Materialia 73 177-185.

[18] Jay Prakash Gavade, Dr. Prakash Ramdasi ,2014) "Experimental Investigation and stastical analysis of the Friction Welding Parameters for the aluminum Alloy 6061-T6 Using Factorial Design Of Experiment”. International Journal of Advanced Information in Arts, Science \& Management (IJAIASM) Vol.1, No.2.

[19]Mrityunjoy Hazra, Kotipalli Srinivasa Rao,Gankidi Madhusudhan Reddy,(2014) "Friction welding of a nickel free high nitrogen steel:influence of forge force on microstructure, mechanical properties and pitting corrosion resistance" j mater res technol;3(1):90-100.

[20]Mohamed Harraz1a,Mustafa Awd1b, Adham Al-Sayyad,( 2014) "A Review of Different Methods for Joining of Bi-Metallic Materials by Friction Welding” International Journal of Engineering Research \& Technology (IJERT) Vol. 3 Issue 1,.

[21]S.T. Selvamani, K. Palanikumar, (2014) "Optimizing the friction welding parameters to attain maximum tensile strength in AISI 1035 grade carbon steel rods", Measurement,

[22]Amit Handa and Vikas Chawla, (2014) "Experimental evaluation of mechanical properties of friction welded AISI steels", Cogent Engineering, 1: 936996.

[23]Radosław Winiczenkoa, Mieczysław Kaczorowski, (2013) "Friction welding of ductile iron with stainless steel" ,Journal of Materials Processing Technology 213:453- 462.

[24]Dalip Kumar ${ }^{1}$, Antariksha Verma ${ }^{2}$, Sankalp Kulshrestha ${ }^{3}$, Prithvi Singh ${ }^{4}$ (2013) Microstructure and Mechanical Properties of Mild Steel-copper Joined By Friction Welding Volume 4, Issue 5.

[25]Hazman Seli,Mokhtar Awang, Ahmad Izani Md. Ismail,Endri Rachman, Zainal Arifin Ahmad(2013) "Evaluation of Properties and FEM Model of the Friction Welded Mild Steel-Al6061-Alumina" Materials Research.; 16(2): 453467.

[26]Shubhavardhan R.N \& Surendran Sfriction (2012) , "Welding To Join Stainless Steel And Aluminum Materials" ,International Journal of Metallurgical \& Materials Science and Engineering ISSN 2278-2516 Vol.2, Issue 3 Sep pp. 53-73.

[27] E.Ravikumar, N.Arunkumar, and Sunnapu Gunhie Samhit,(2013) “Characterization of Mechanical Properties of Aluminum (AA6061-T6) By Friction Welding” 3rd International Conference on Mechanical, Automotive and Materials Engineering, Singapore.

[28] Sandeep Kumar1*, Rajesh Kumar' and Yogesh Kumar Singla ${ }^{2}$,(2012) “To Study The Mechanical Behaviour Of Friction Welding Of Aluminium Alloy And Mild Steel” Int. J. Mech. Eng. \& Rob. Res.

[29]Shubhavardhan $\mathrm{RN}^{1}$, Surendran $\mathrm{S}^{2}$ (2012)“ Friction Welding to Join Dissimilar Metals” International Journal of Emerging Technology and Advanced Engineering. 
[30]M.B. Uday, M.N. Ahmad Fauzi, H. Zuhailawati, A.B. Ismail, (2011) "Effect of welding speed on mechanical strength of friction welded joint of YSZ-alumina composite and 6061 aluminium alloy" Materials Science and Engineering A 528 4753-4760.

[31]M.N. Ahmad Fauzi, M.B. Uday, H. Zuhailawati,A.B. Ismail, (2010) "Microstructure and mechanical properties of alumina-6061 aluminum alloy joined by friction welding" Materials and Design 31 670-676.

[32]Hazman Seli,Ahmad Izani Md. Ismail, Endri Rachman, Zainal Arifin Ahmad,(2010) "Mechanical evaluation and thermal modelling of friction welding of mild steel and aluminum”, Journal of Materials Processing Technology 210 :1209-1216.

[33]Eder Paduan Alves, Francisco Piorino Neto, Chen Ying An, (2010) "Welding of AA1050 aluminum with AISI 304 stainless steel by rotary friction welding process" J. Aerosp.Technol. Manag., São José dos Campos, Vol.2, No.3, pp. 301-306, Sep-Dec.

[34]H. Khalid Rafi, G.D. Janaki Ram, G. Phanikumar, K. Prasad Rao, (2010)“Microstructure and tensile properties of friction welded aluminum alloy AA7075-T6" Materials and Design 31 2375-2380.

[35]P.D. Sketchley, P.L. Threadgill, I.G. Wright,(2002) "Rotary friction welding of an Fe3Al based ODS alloy". Materials Science and Engineering A329-331;756-762. 